https://doi.org/10.15407/ujpe63.8.709

S.YU. KUTOVYY, ${ }^{1}$ R.S. SAVCHUK, ${ }^{1}$ N.V. BASHMAKOVA, ${ }^{1}$ D.M. HOVORUN,${ }^{2}$ L.A. ZAIKA ${ }^{2}$

1 Taras Shevchenko National University of Kyiv, Faculty of Physics

(60, Volodymyrs'ka Str., Kyiv 01601, Ukraine; e-mail: sangulaire@gmail.com)

2 Institute of Molecular Biology and Genetics, Nat. Acad. of Sci. of Ukraine

(150, Academician Zabolotnyi Str., Kyiv 03145, Ukraine)

\title{
MECHANISMS AND PARAMETERS OF THE BINDING OF AMITOZINOBERAMID TO DNA IN THE AQUEOUS SOLUTION
}

\begin{abstract}
The interaction between the amitozinoberamid preparation (thiotepa-alkylated berberine) and a DNA macromolecule in the aqueous solution has been studied, by using the optical spectroscopy methods: electron absorption and fluorescence. The dependence of spectral characteristics on the concentration ratio $\mathrm{N} / \mathrm{c}$ between the DNA base pairs and the ligand molecules is plotted. Using the system of modified Scatchard and McGhee-von Hippel equations, the parameters of the binding of amitozinoberamid to DNA are determined. A comparative analysis of the $D N A$ interaction with amitozinoberamid, on the one hand, and berberine and sanguinarine alkaloids, on the other hand, is carried out. The structure and the spectra of electron absorption of thiotepa, berberine, and amitozinoberamid molecules are calculated in the framework of the density functional theory at the DFT B3LYP/6-31G(d,p) level.
\end{abstract}

Keywords: DNA, amitozinoberamid, berberine, thiotepa, McGhee-von Hippel binding equations.

\section{Introduction}

The results obtained, when studying the binding of various compounds to a DNA macromolecule, have a wide range of applications. For instance, the research of the DNA interaction with low-molecular ligands is important for the development of antitumor and immunomodulatory drugs, fluorescent probes, and so forth.

The creation of low-toxic preparations with a broad therapeutic effect is a challenging task for modern pharmacy. This task cannot be successfully fulfilled, if there is no understanding of the physical mechanisms governing the interaction of those compounds with DNA at the molecular level. Those preparations include a number of celandine alkaloids (berberine, sanguinarine, and others) that reveal the antiviral, antiinflammatory, bactericidal $[1,2]$, and antitumor [3-7] properties. Owing to their plant origin, those alkaloids have a relatively low toxicity. The antitumor effect of alkaloids is associated with their ability

(C) S.YU. KUTOVYY, R.S. SAVCHUK, N.V. BASHMAKOVA, D.M. HOVORUN,

L.A. ZAIKA, 2018

ISSN 2071-0194. Ukr. J. Phys. 2018. Vol. 63, No. 8 to build into the DNA double helix and, in such a way, to violate and to block its functioning.

This work is a logic continuation of our previous researches [8-12], which dealt with the interaction between a DNA macromolecule and low-molecular compounds, and were performed making use of optical methods such as electron absorption, fluorescence, and Raman scattering. In this work, the main attention is focused on the study of the interaction between the amitozinoberamid preparation (berberine, the celandine alkaloid, alkylated with thiotepa) and a DNA macromolecule in the aqueous solution. Since the amitozinoberamid (in essence, modified berberine) medicament is a successor of its predecessors - in particular, berberine and amitozine (the latter is a complex preparation containing celandine alkaloids, including berberine and sanguinarine) - it is reasonable to make a comparative analysis of the DNA interaction with the amitozinoberamid preparation and with the berberine and sanguinarine alkaloids, the latter were studied by us earlier [8-11]. Recent researches showed that modified alkaloids, including modified berberine [13, 14], bind more strongly to DNA. No systematic studies of 
<smiles>COc1ccc2cc3[n+](cc2c1OC)CCc1cc2c(cc1-3)OCO2</smiles><smiles>S=P(N1CC1)(N1CC1)N1CC1</smiles>

$b$

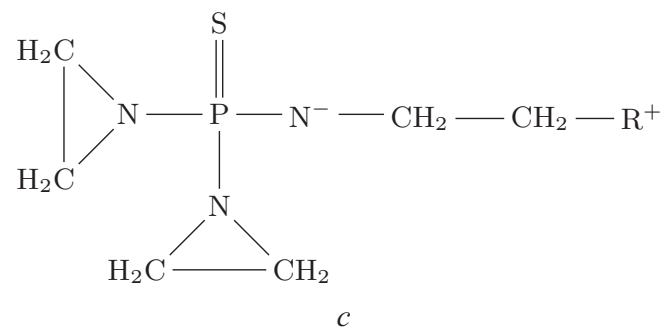

Fig. 1. Structural formulas of berberine (a), thiotepa (b), and amitozinoberamid (c) $\left(R^{+}\right.$-berberine)

the amitozinoberamid-DNA interaction using physical methods, in particular, optical spectroscopy, were carried out earlier.

Amitozinoberamid of $\mathrm{N}^{\prime}, \mathrm{N}^{\prime \prime}, \mathrm{N}^{\prime \prime \prime}$-tri-(N-berberinoetyleneamid)thiophosphoric acid is a preparation obtained at the Institute of Molecular Biology and Genetics of the National Academy of Sciences of Ukraine (IMBG NASU). It is a result of the alkylation of berberine $\left(\mathrm{C}_{20} \mathrm{H}_{19} \mathrm{NO}_{5}\right.$, an alkaloid of the isoquinoline group) with thiotepa [15]; i.e., amitozinoberamid is a modified berberine. The berberine molecule has three unsaturated rings and a partially saturated one that contains a charged nitrogen atom $\mathrm{N}^{+}$. Because of the partially saturated ring, the berberine molecule is a little bent and has a half- armchair configuration $[16,17]$. Thiotepa (triethylene thiophosphoramide, 1, 1', $1^{\prime \prime}$-phosphorothiolectriaziridine) is an organophosphorous alkylating agent. As a medical preparation, it demonstrates an antitumor activity, although it is very toxic [18]. The thiotepa formula is $\mathrm{SP}\left(\mathrm{NC}_{2} \mathrm{H}_{4}\right)_{3}$. It is composed of three aziridine molecules, which are bound with the phosphor and sulfur atoms. Thiotepa is connected to berberine via the $\mathrm{C} 13$ atom. The structural formulas of the berberine, thiotepa, and amitozinoberamid molecules are exhibited in Fig. 1.

In this work, we obtained the dependences of the spectral characteristics of amitozinoberamid (and, as an auxiliary result, thiotepa) on the parameter $N / c$, the ratio between the number of DNA base pairs and the number of ligand molecules; the other widely used notation for this quantity is $P / D$, i.e. Phosphate/Drug. Spectral manifestations of the interaction of amitozinoberamid (and thiotepa) with DNA are detected. The data obtained with the use of the spectral methods are applied to calculate the binding parameters. The calculations are carried out, by using the system of modified Scatchard and McGheevon Hippel equations.

\section{Experimental Specimens and Methods}

In this work, the aqueous solutions of the amitozinoberamid (AmBe, IMBG NASU) and thiophosphamide (Thio, IMBG NASU) preparations were used. We also used the DNA of calf thymus ("Serva", Germany) with the average molar mass of a base pair of about $650 \mathrm{~g} / \mathrm{mol}$ and a high purification degree. In auxiliary experiments, the DNA of salmon sperm ("Sigma-Aldrich", USA) with a low purification degree (7\% of proteins) was used. Water for injection ("Darnitsa", Ukraine) was applied as a solvent. All examined substances were used without their additional purification.

Specimens were prepared, by using mechanical samplers of the MicroPette type ("ULAB", Ukraine). The charge mass was determined, by using an analytical torsion balance ("Techniprot WT", Poland) with an accuracy of $0.02 \mathrm{mg}$. Stock (concentrated) solutions of examined preparations and DNA were prepared by dissolving the preparation charge in water.

The concentration dependences for the AmBe + + DNA and Thio + DNA solutions were obtained by varying the DNA concentration and leaving the preparation concentration unchanged. The ratio be-

ISSN 2071-0194. Ukr. J. Phys. 2018. Vol. 63, No. 8 
tween the molar concentrations of DNA and the preparation, $N / c$, was reckoned in the number of DNA nucleotide pairs per one ligand molecule.

The absorption spectra were registered on a spectrophotometer "Specord UV VIS" (Carl Zeiss, Germany) in a wavelength interval of 200-700 nm with a resolution of about $1 \mathrm{~nm}$. The fluorescence spectra were obtained in an interval of 300-800 nm, by using a fluorometer "Cary Eclipse" (Varian, Australia). The spectral width of the slit for measuring the fluorescence parameters amounted to $5 \mathrm{~nm}$.

\section{Experimental Results}

The specific manifestations of the interaction between small ligands and DNA in the absorption and fluorescence spectra include such phenomena as the hypo- or hyperchromism of ligand absorption bands, the "red" or "blue" shifts of the absorption and fluorescence maxima, and the change of the fluorescence quantum yield.

\subsection{Absorption}

\subsubsection{Thiotepa}

The experimental absorption spectrum of thiotepa is located in the interval $\lambda \leq 230 \mathrm{~nm}$, and the corresponding band maximum is observed at $\lambda \leq 200 \mathrm{~nm}$, i.e., the registration was carried out at the technical frontier of a spectrometer "Specord UV VIS". Therefore, the absorption spectrum of thiotepa was calculated (after the molecular structure optimization), by using the density functional method at the theoretical level DFT B3LYP/6-31G(d,p). Taking into account that numerical calculation methods give a little shifted values for the positions of absorption maxima, we may say that the calculation and experimental results correlated quite well.

The calculated complex doublet absorption band of thiotepa lies in an interval of 140-220 nm. Its main maxima are located at about 160 and $190 \mathrm{~nm}$. Its long-wave component almost coincides with the position of the experimental band with a maximum at about $200 \mathrm{~nm}$. Figure 2 demonstrates the experimental and calculated electron absorption spectra of thiotepa.

\subsubsection{Berberine}

The manifestations of the interaction of berberine with DNA in optical spectra were described in our

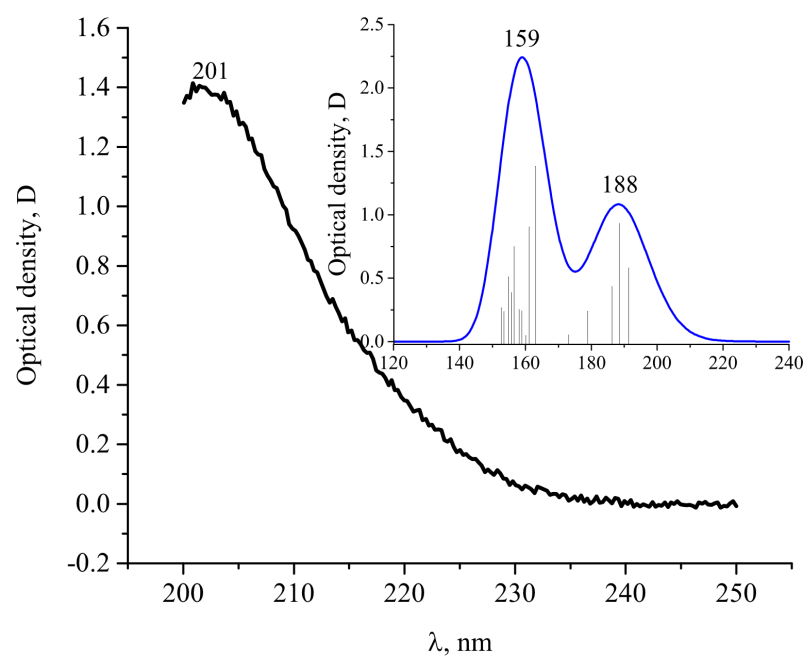

Fig. 2. Experimental (the main panel) and theoretical (calculated by the DFT method, in the inset) absorption spectra of thiotepa

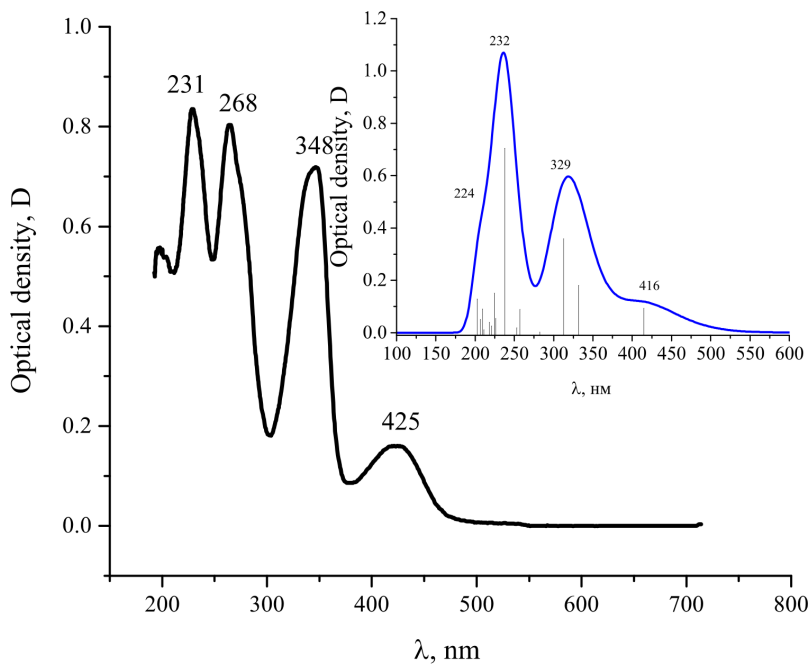

Fig. 3. Experimental [8] (the main panel) and theoretical (calculated by the DFT method, in the inset) absorption spectra of berberine

works $[8,9]$. Here, for the sake of completeness, we present only the electron absorption spectra (Fig. 3).

The absorption spectrum of berberine lies in the interval $\lambda \leq 500 \mathrm{~nm}$. Its first long-wave maximum is located at $\lambda_{\max } \approx 425 \mathrm{~nm}$. Further, in an interval of 200-400 nm, there are three combined - at least twocomponent - absorption bands with the maxima at about 348, 268, and $231 \mathrm{~nm}$.

The absorption spectrum of berberine calculated in the framework of the DFT also contains four 


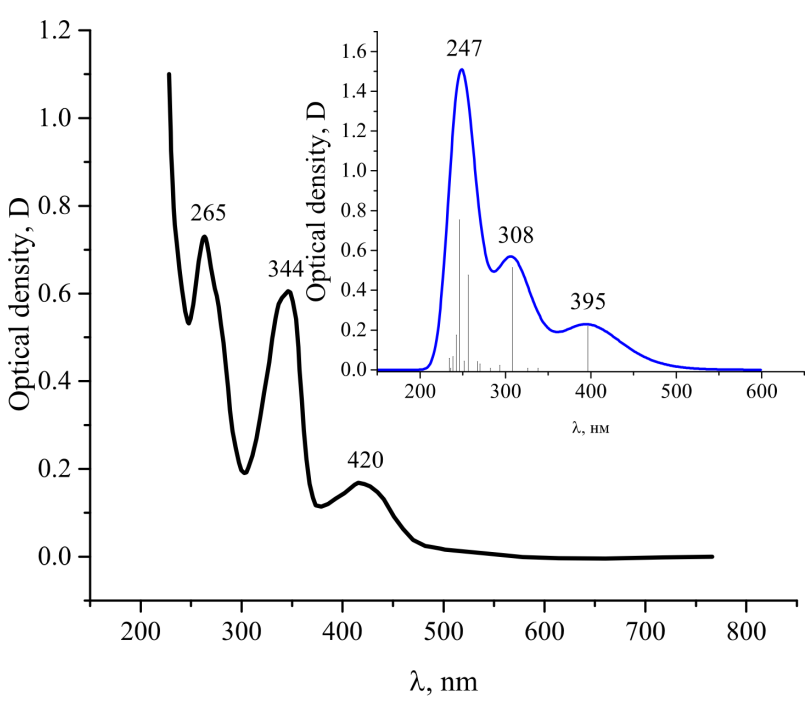

Fig. 4. Experimental (the main panel) and theoretical (calculated by the DFT method, in the inset) absorption spectra of amitozinoberamid

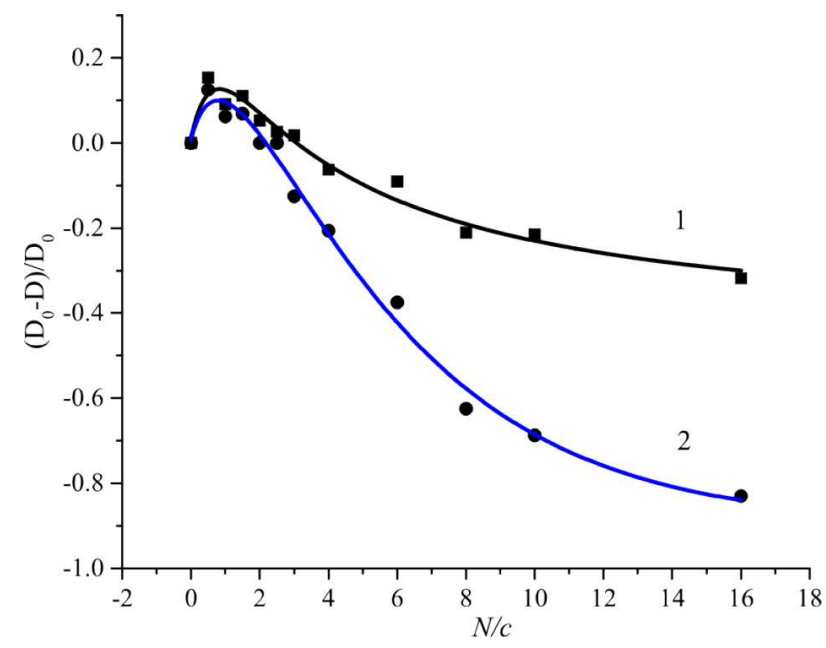

Fig. 5. Dependences of the optical density of amitozinoberamid on $N / c$ for the 344-nm (1) and 420-nm (2) bands

bands (see the inset in Fig. 3). One can observe a good correlation between the experimental and calculated spectra.

When DNA is added and the ratio $N / c$ increases, the absorption spectra demonstrate hypochromic changes of the optical density (up to $30 \%$ ) and the "red" shift of absorption maxima up to $22 \mathrm{~nm}$ [8].

\subsubsection{Amitozinoberamid}

In order to avoid the reabsorption and aggregation phenomena, the AmBe concentrations did not exceed
$10^{-3} \mathrm{~mol} / \mathrm{l}$, when measuring absorption spectra. A linear dependence of the optical density at the absorption band maxima on the AmBe concentration was observed in the examined interval. Hence, the Bouguer-Lambert-Beer law was obeyed, and the solution was molecular.

The absorption spectrum of amitozinoberamid (Fig. 4) lies in an interval up to $600 \mathrm{~nm}$. It consists of a few combined bands, including two long-wave bands with the maxima at about 420 and $344 \mathrm{~nm}$. When DNA is added and the ratio $N / c$ increases, the both bands demonstrate changes in their optical density and have the "red" shift of their absorption maxima. The corresponding relative changes are larger for the long-wave band $(420 \mathrm{~nm})$. Those changes testify to the interaction of DNA with the ligand, as well as to the possible binding.

The magnitude of the "red" shift was about $15 \mathrm{~nm}$ for the 344-nm band and about $20 \mathrm{~nm}$ for the $420-\mathrm{nm}$ one. The shift magnitude changed non-monotonically at that: first, it rapidly grew to the maximum value and then decreased and formed a plateau.

The optical density of both absorption bands also changed non-monotonically (Fig. 5). The behavior of the optical density is similar to that of the "red" shift. The hypochromic effect (the optical density reduction) was observed at low $N / c$-values $(N / c<2)$, and the hyperchromic one (the optical density growth) at $N / c \geq 2$, which testifies to different mechanisms of complex formation in the two indicated $N / c$-intervals. Note that such a type of the dependence on $N / c$ was also observed for changes in the fluorescence intensity (see below).

By comparing the absorption spectra of thiotepa, berberine, and amitozinoberamid, a conclusion can be drawn that the absorption band of amitozinoberamid in an interval of $220-200 \mathrm{~nm}$ is associated with the "thiotepa" component of the amitozynobamid molecule, whereas the other, longer-wave bands with the "berberine" one. The AmBe absorption bands are shifted by $3-5 \mathrm{~nm}$ toward short waves with respect to the corresponding Be bands. This result is confirmed by calculations in the framework of the DFT method.

\subsection{Fluorescence}

\subsubsection{Thiotepa}

For a better understanding of the interaction between amitozinoberamid and DNA, auxiliary experiments 


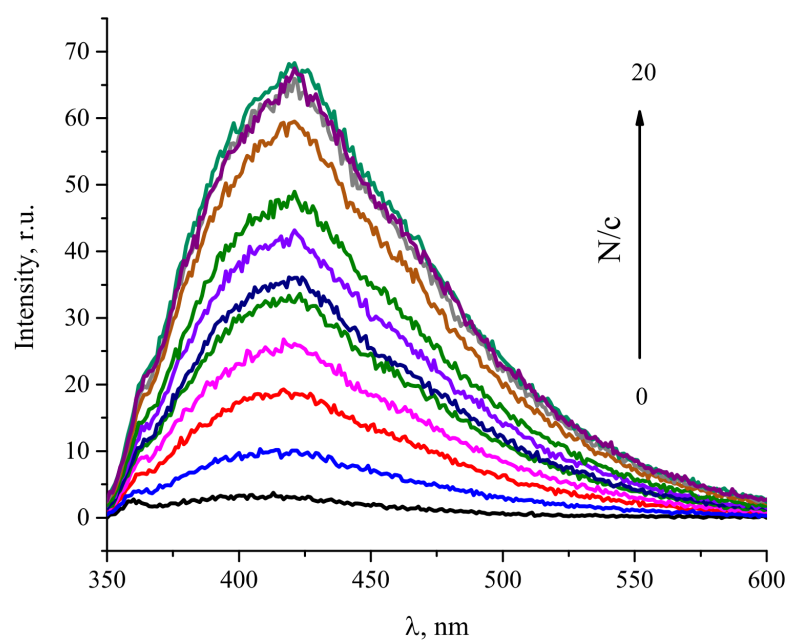

Fig. 6. Fluorescence spectra of thiotepa for various $N / c=$ $=0 \div 20$. The thiotepa concentration is $1.06 \times 10^{-3} \mathrm{M}, \lambda_{\mathrm{ex}}=$ $=260 \mathrm{~nm}$

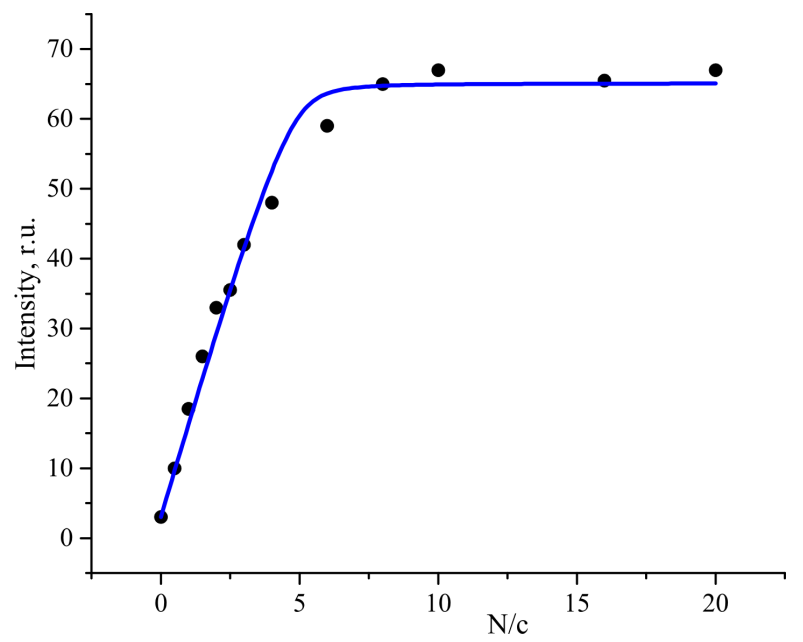

Fig. 7. Dependence of the thiotepa fluorescence intensity on $N / c$

were carried out in order to study the interaction of DNA with one of the amitozinoberamid components, thiophosphamide. The latter has a small molecule interacting with DNA. The fluorescence spectrum of thiotepa lies in an interval of 300-600 nm. It consists of two closely located and unresolved bands with a complex structure and a maximum at about $410 \mathrm{~nm}$ (Fig. 6).

The fluorescence of the thiotepa-DNA complex was characterized by the growth of the radiation emission intensity by a factor of 10-20 as compared with free thiotepa, depending on the excitation wavelength,

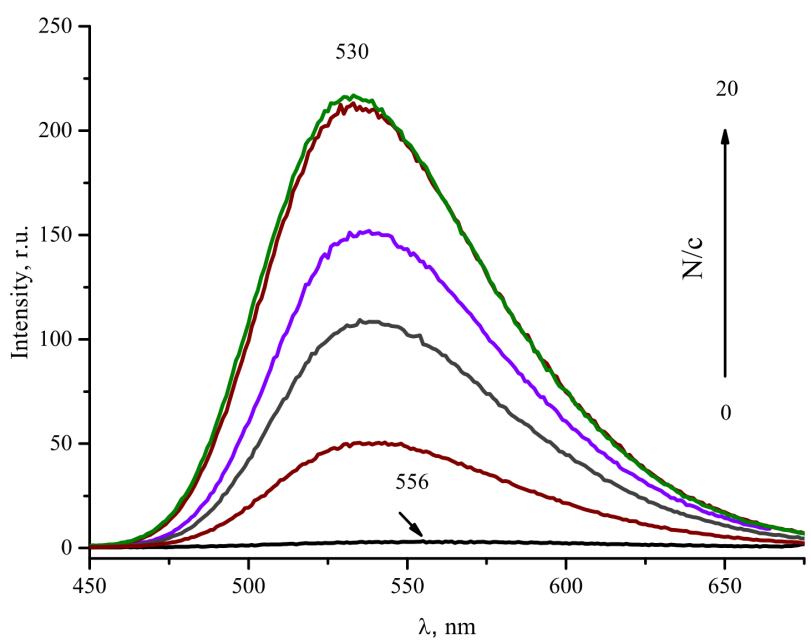

Fig. 8. Fluorescence spectra of berberine for various $N / c=$ $=0 \div 20$ [8]. The berberine concentration is $4.1 \times 10^{-5} \mathrm{M}$, $\lambda_{\mathrm{ex}}=450 \mathrm{~nm}$

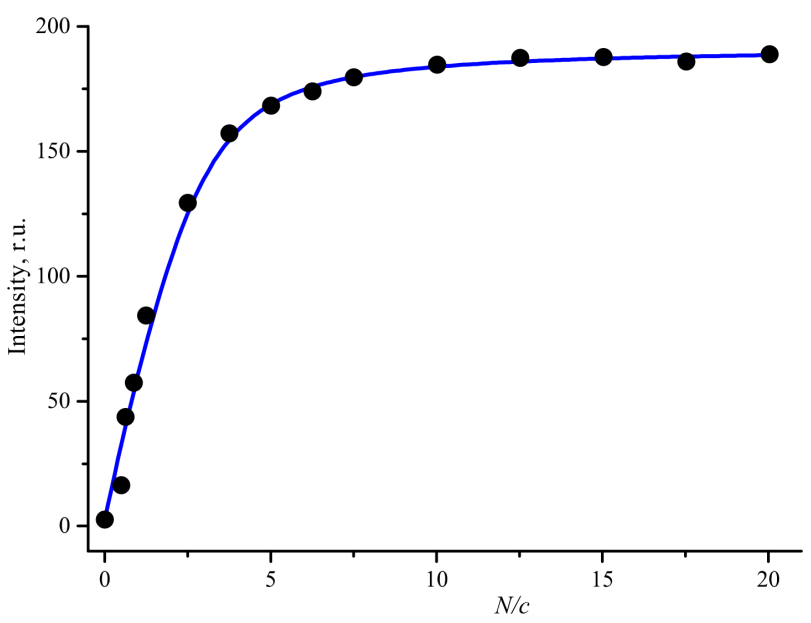

Fig. 9. Dependence of the berberine fluorescence intensity on $N / c[8]$

concentration, and DNA type (Fig. 7). A shift of the fluorescence peak by about $10 \mathrm{~nm}$ toward the redwave interval was also observed.

\subsubsection{Berberine}

The fluorescence spectrum of berberine lies in an interval of 450-700 $\mathrm{nm}$. It consists of two closely located unresolved bands with a complex structure and a maximum at about $556 \mathrm{~nm}$ (Fig. 8). The fluorescence of the berberin-DNA complex was characterized by the radiation emission intensity growth by a factor of 100-200 as compared with free berberine, de- 


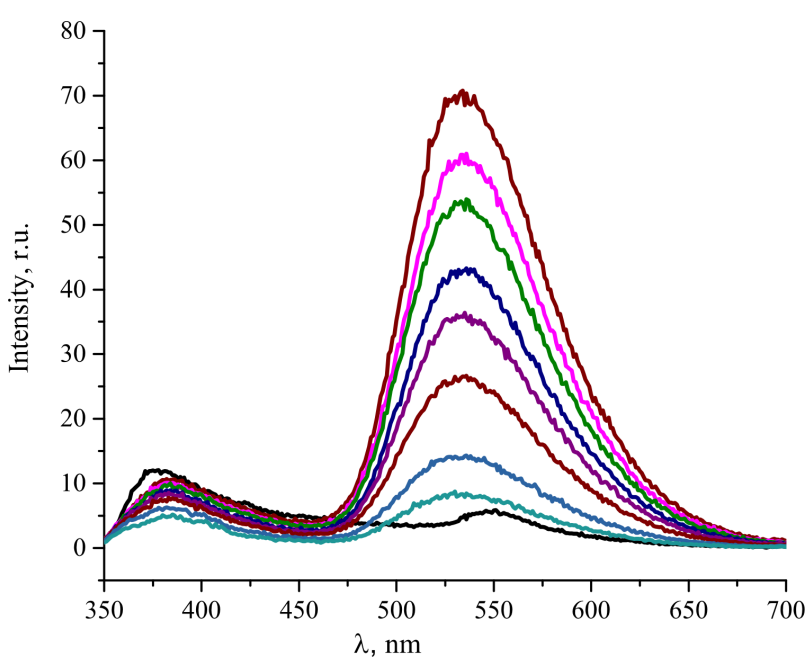

Fig. 10. Fluorescence spectra of amitozinoberamid for various $N / c=0 \div 16$. The AmBer concentration is $4.24 \times 10^{-4} \mathrm{M}$, $\lambda_{\text {ex }}=300 \mathrm{~nm}$

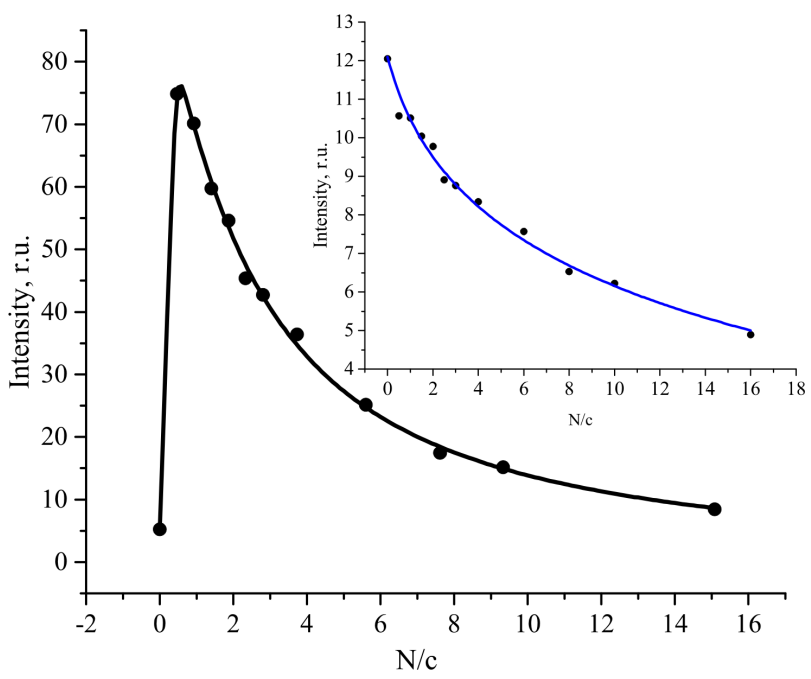

Fig. 11. Dependences of the amitozinoberamid fluorescence intensity on $N / c$ in the $550-\mathrm{nm}$ (the main panel) and $375-\mathrm{nm}$ (the inset) bands

pending on the excitation wavelength, concentration, and DNA type (Fig. 9). A shift of the fluorescence peak by up to $30 \mathrm{~nm}$ toward the blue wavelengths was also observed.

The fluorescence intensity growth occurs due to the fixation of ligand molecules on the DNA matrix. The formation of this complex diminishes the number of vibrational degrees of freedom, which decreases the probability of non-radiative excitation relaxation, so that the vibrational relaxation during the lifetime of the excited state is also less effective. As a result, the quantum yield of fluorescence increases.

\subsubsection{Amitozinoberamid}

The fluorescence spectrum of amitozinoberamid consists of two combined bands: a short-wave band with a maximum at about $375 \mathrm{~nm}($ at $N / c=0)$ and a long-wave band with a maximum at $550 \mathrm{~nm}$ (Fig. 10). The position of the short-wave band almost coincides with the fluorescence band of thiotepa, and the long-wave band is close by its shape and position to the berberine fluorescence band [9]. Taking those facts into account and analyzing the fluorescence excitation spectra, we may conclude that the contributions of the "thiotepa" and "berberine" components of the molecule (the excitation transfer between them is hampered) to the AmBe fluorescence spectrum can be distinguished.

If DNA is added, the spectra change. Namely, the radiation emission intensity increases, and the maxima shift: the 375-nm "thiotepa" band by up to $10 \mathrm{~nm}$ toward the "red" wavelengths, and the 550-nm "berberine" band by up to $20 \mathrm{~nm}$ toward the "blue" wavelengths, which corresponds to the behavior of the thiotepa and berberine fluorescence bands. As was in the absorption spectra when DNA was added, the changes in the amitozinoberamid fluorescence intensity and the shifts of bands' maxima are nonmonotonic functions of the $N / c$ ratio. In particular, if this parameter is small $(N / c \leq 1)$, the intensity drastically increases to a maximum; afterward, the intensity decreases and forms a plateau. The changes in the fluorescence intensity and the shifts of the band maxima are observed for both AmBe fluorescence bands. Therefore, we may assume that the both components of the AmBe molecule are involved into the process of interaction with DNA.

\section{Binding Parameters}

In order to determine the binding parameters, we developed and used the software program BindFit, which makes it possible to analyze direct experimental data making no use of "linearizing" transformations. As a result, the accuracy of the parameter determination for processes that are characterized by a nonlinear binding curve even after the linearization 
was made higher. The main idea of this program consists in the approximation of experimental data by means of corresponding binding equations.

A classical binding equation is the Scatchard equation [19]

$\frac{\nu}{c_{f}}=K(1-\nu)$.

Here, $\nu$ is the ratio between the concentration of bound ligands $c_{b}$ and the total number of binding sites $N, c_{f}$ the concentration of free ligands, and $K$ the binding constant. It is evident that the dependence of $\nu / c_{f}$ on $\nu$ has to be linear, and the binding constant is determined from the slope of the straight line. If a ligand molecule occupies more than one binding site on the matrix, namely, $n$ sites, the equations is rewritten in the form

$\frac{\nu}{c_{f}}=K(1-n \nu)$.

The original equation was derived for proteins, and its application to analyze the molecular binding to DNA is not always proper, because the number of free binding sites can be underestimated, so that the binding parameters can be determined improperly (in particular, the binding constant value may be overestimated by a factor of $2 n[20])$. Note that, for the binding processes of small ligands to DNA, those dependences remain nonlinear, as a rule, even after the linearization.

Using the methods of probability theory, McGhee and von Hippel [20] extended the Scatchard approach onto the cases $n>1$. The number of free binding sites was also determined correctly. The McGhee-von Hippel equation is as follows:

for the non-cooperative binding,

$\frac{\nu}{c_{f}}=K(1-n \nu)\left(\frac{1-n \nu}{1-(n-1) \nu}\right)^{n-1}$,

and, for the cooperative binding,

$$
\begin{aligned}
& \frac{\nu}{c_{f}}=K(1-n \nu)\left(\frac{(2 \omega-1)(1-n \nu)+\nu-R}{2(\omega-1)(1-n \nu)}\right)^{n-1} \times \\
& \times\left(\frac{1-(n+1) \nu+R}{2(1-n \nu)}\right)^{2},
\end{aligned}
$$

where $\omega$ is the cooperativity parameter, and

$R=\sqrt{(1-(n+1) \nu)^{2}+4 \omega \nu(1-n \nu)}$.

ISSN 2071-0194. Ukr. J. Phys. 2018. Vol. 63, No. 8

\subsection{Modified equations}

The concentrations of bound and free ligands are not experimentally observed quantities. What is measured experimentally is the dependences of optical parameters on the concentrations of solution components. As a rule, an optical parameter is calculated as the sum of contributions made by ligands in different states: bound and free. As an optical parameter, it is convenient to choose either the fluorescence intensity or the optical density (in the absorption spectra).

If a ligand can only be in one of two states (free or bound), i.e. only one type of binding sites is realized, then the expression for the optical parameter is relatively simple and allows the concentrations of free and bound ligands to be determined directly:

$A=\frac{c_{f}}{c} A_{f}+\frac{c_{b}}{c} A_{b}$

where $A$ is the optical parameter value for the mixture, $c$ the total concentration of ligands, $A_{f}$ the optical parameter value for free ligands, $c_{f}$ the concentration of free ligands, $A_{b}$ the optical parameter value for bound ligands, and $c_{b}$ the concentration of bound ligands $\left(c=c_{f}+c_{b}\right)$. Knowing the values of $A_{f}$ and $A_{b}$ (the former is determined for the pure ligand solution, and the latter is potentially determined for a ligand solution of a significant DNA excess), we can determine $c_{f}$ and $c_{b}$, and afterward change to the Scatchard coordinates.

If a ligand can be in one of three states (free, bound at a site of type 1 , and bound at a site of type 2; i.e. there are two types of binding sites), then the expression for the optical parameter is more complicated:

$A=\frac{c_{f}}{c} A_{f}+\frac{c_{b}^{(1)}}{c} A_{b}^{(1)}+\frac{c_{b}^{(2)}}{c} A_{b}^{(2)}$,

where $A_{b}^{(i)}$ are the optical parameters of ligands that are bound at the site of type $i(i=1,2)$, and $c_{b}^{(i)}$ are the corresponding ligand concentrations. In this case, it is difficult to determine the concentrations of ligands in each state and, accordingly, to change to the Scatchard coordinates, because it is impossible to determine $A_{b}^{(1)}$ and $A_{b}^{(2)}$ by direct measurements. However, when experimental data are approximated, those quantities can be calculated together with other parameters [9]. 
The equations written in terms of the Scatchard variables $\nu$ and $\nu / c_{f}$ are not convenient for a numerical analysis, because those variables are related to experimental optical parameters (the fluorescence intensity, the optical density, and others) in a quite complicated manner. Moreover, the binding parameters are determined from the equations for the Scatchard variables with a rather large error. This occurs because the linearization "according to Scatchard" in the general case of nonlinear dependences gives rise to a significant distortion of the experimental errors and, accordingly, the determination accuracy of binding parameters, so that the latter are better to be determined from initial nonlinearized curves. Therefore, in order to analyze the experimental data and approximate them directly, i.e. in terms of experimental variables, Eqs. (3) and (4) were modified [9] and used in the form of equations for the concentration of bound ligands $c_{b}$.

For the processes with one type of binding sites, the basic equations are the McGhee-von Hippel equations transformed from their original form to a form that contains only the variables directly associated with the experiment. As was said above, what is typically measured in experiment is the dependence of a certain optical parameter on the concentration ratio between the solution components. Most often, this is the ratio $N / c$ between the total concentration of binding sites and the total concentration of ligands. By its origin, this parameter is reciprocal to $\nu$, whereas it is the component concentrations rather than the concentrations of bound or free ligands that are known quantities. Therefore, for the numerical processing, it is more appropriate to use such variables as the total concentrations of ligands, $c$, and binding sites, $N$. In this case, the equation contains one unknown variable to be sought numerically.

After some transformations [9], the McGhee-von Hippel equations bring about the following equations for the variable $c_{b}$ :

for the noncooperative binding,

$K\left(c-c_{b}\right)\left(N-\nu c_{b}\right)\left(\frac{N-n c_{b}}{N-(n-1) c_{b}}\right)^{n-1}-c_{b}=0$,

and, for the cooperative binding,

$K\left(c-c_{b}\right)\left(N-n c_{b}\right) \times$

$\times\left(\frac{(2 \omega-1)\left(N-n c_{b}\right)+c_{b}-R^{\prime}}{2(\omega-1)\left(N-n c_{b}\right)}\right) \times$
$\times\left(\frac{N-(n+1) c_{b}+R^{\prime}}{2\left(N-n c_{b}\right)}\right)-c_{b}=0$,

where

$R^{\prime}=\sqrt{\left(N-(n+1) c_{b}\right)^{2}+4 \omega c_{b}\left(N-n c_{b}\right)}$.

Equations (7) and (8) were programmed in the presented form to be solved numerically. This enabled us to deal with the quantity $c_{b}$ as the function $c_{b}=$ $=c_{b}(N, c ; K, n)$.

Processes with binding sites of two types are described by a system of two equations. The latter should involve an interdependence or an independence of binding processes for the ligands that occupy the same binding site (i.e. a base pair and phosphates). If the parameter $N$ describes the concentration of the DNA base pairs, then $2 N$ binding sites correspond to the binding of the first type (with phosphate), and $N$ binding sites correspond to the binding of the second type (intercalation). A direct transition of bound ligands from type- 1 sites to type- 2 sites is assumed to be impossible.

The approximation of our experimental data for AmBe was the best, when the system of modified Scatchard equations for external binding and the McGhee-von Hipple equations for the intercalation was applied. The system describes two interdependent binding processes for ligands that occupy the same binding site. Intercalation into the gap between the base pairs is allowed only if ligands are not bound to both phosphates in this gap; and vice versa, binding with the phosphates is possible only if the ligand has not intercalated into the relevant gap. Furthermore, there must be at least $n-1$ free gaps between two intercalated ligands. This model is described by the following system of equations:

$$
\left\{\begin{array}{l}
c_{b}^{(1)}=K_{1}\left(c-c_{b}^{(1)}-c_{b}^{(2)}\right)\left(2 N-c_{b}^{(1)}\right)\left(1-\frac{c_{b}^{(2)}}{N}\right), \\
c_{b}^{(2)}=K_{2}\left(c-c_{b}^{(1)}-c_{b}^{(2)}\right)\left(N-n c_{b}^{(2)}\right) \times \\
\times\left(\frac{N-n c_{b}^{(2)}}{N-(n-1) c_{b}^{(2)}}\right)^{n-1}\left(1-\frac{c_{b}^{(1)}}{2 N}\right)^{2} .
\end{array}\right.
$$

One can see that the equations for interdependent processes contain an additional factor

$$
\left(1-\frac{c_{b}^{(1)}}{2 N}\right)^{2}
$$

which was considered in work [9] in detail.

ISSN 2071-0194. Ukr. J. Phys. 2018. Vol. 63, No. 8 


\subsection{Binding parameters}

The binding parameters can be determined in the most convenient way, by using the data describing the changes in the optical density (in the absorption spectra) and in the fluorescence intensity (at the band maximum). In our experiments, more accurate data were obtained from the fluorescence spectra. Accordingly, the results of corresponding approximations were also more accurate.

\subsubsection{Thiotepa}

The fluorescence spectra of thiotepa at various $\mathrm{N} / \mathrm{c}$ values are shown in Fig. 6. The dependence of the fluorescence intensity at the band maximum on the parameter $N / c$ (the binding curve) is plotted in Fig. 7. One can see that the fluorescence intensity reaches a maximum at $N / c \approx 10$, and the dependence forms a plateau, which means that the maximum possible number of ligand molecules are already in the bound state.

The values of binding parameters can be obtained from the dependence of the fluorescence intensity on the concentration ratio, by using the BindFit soft program. In this case, the experimental results were better described by Eq. (8), which makes allowance for one type of binding, intercalation (possibly partial), and the binding was found to be anticooperative. The parameters obtained for the binding of thiotepa to DNA are as follows:

- the binding constant for the intercalation process $K_{2}=(0.10 \pm 0.04) \times 10^{6} \mathrm{l} / \mathrm{mol}$,

- the average number of binding sites occupied by a ligand $n=3.6 \pm 0.4$,

- the cooperativity parameter $\omega=0.30 \pm 0.05$.

Note that, in work [21] within the quantumchemical calculation methods, the selective binding of thiotepa to deoxyguanosine monophosphate (dGMP) by means to a strong hydrogen bond of the type N$\mathrm{H} \cdots \mathrm{N}$ was demonstrated.

\subsubsection{Berberine}

The experimental data were approximated, by using the modified McGhee-von Hippel equation (8) for the cooperative binding. The binding curve for berberine is shown in Fig. 9. The following binding parameters were obtained:

- $K_{2}=(5.2 \pm 0.2) \times 10^{4} \mathrm{l} / \mathrm{mol}$,
- $n=1.9 \pm 0.1$,

- $\omega=1.3 \pm 0.2$.

The value $n \approx 2$ means that one alkaloid molecule occupies two DNA base pairs, which testifies to the intercalation mechanism of berberine binding to DNA. An insignificant cooperativity value may indicate a certain untwisting of the DNA helix at the intercalation sites. For more information concerning the berberine binding, see work [8].

\subsubsection{Amitozinoberamid}

The fluorescence spectrum of amitozinoberamid is composed of two bands (Fig. 10). The dependences of the intensities of those bands on the concentration ratio between the ligand and DNA, i.e. the binding curves, are exhibited in Fig. 11.

According to the experimental data, it was found that AmBer is characterized by two types of binding: intercalation and external binding. In order to determine the binding constants, the system of modified McGhee-von Hippel and Scatchard equations (9), which made allowance for two types of ligand binding to DNA, was used. It was found that both binding processes (intercalation and external binding) reveal themselves in the "berberine" band. Intercalation dominates at small $N / c$-values $(N / c \leq 2)$, and external binding at larger $N / c$-values. Only one type of binding, external, is characteristic of the "thiotepa" part of the molecule in the whole interval of $\mathrm{N} / \mathrm{c}$ values. The parameters of amitozinoberamid binding to DNA are as follows:

- according to the $375-\mathrm{nm}$ band,

- the external binding constant $K_{1}=(0.06 \pm$ $0.02) \times 10^{4} \mathrm{l} / \mathrm{mol}$,

- the average number of binding sites occupied by a ligand $n=2.6 \pm 0.2$;

- according to the $550-\mathrm{nm}$ band,

- $K_{1}=(10.2 \pm 0.8) \times 10^{4} \mathrm{l} / \mathrm{mol}$,

- the binding constant for the intercalation process $K_{2}=(32.8 \pm 6.7) \times 10^{4} \mathrm{l} / \mathrm{mol}$,

- $n=4.1 \pm 0.6$.

Note that the results obtained from the "thiotepa" binding curve are less accurate, because of the low intensity of the $375-\mathrm{nm}$ band. However, the qualitative result obtained here is important: the "thiotepa" component of amitozinoberamid is prone to external binding. 
Binding parameters

\begin{tabular}{|c|c|c|c|c|c|}
\hline \multirow{2}{*}{ Parameter } & \multirow{2}{*}{ Berberine } & \multirow{2}{*}{ Thiotepa } & \multicolumn{2}{|c|}{ Amitozinoberamid } & \multirow{2}{*}{ Sanguinarine } \\
\cline { 3 - 5 } & & & $375 \mathrm{~nm}$ (Tio-band) & $550 \mathrm{~nm}(\mathrm{Be}-\mathrm{band})$ & \\
\hline$K_{1}$ & - & - & $(0.06 \pm 0.02) \times 10^{4}$ & $(10.2 \pm 0.8) \times 10^{4}$ & $(2.5 \pm 0.4) \times 10^{6}$ \\
$K_{2}$ & $(5.2 \pm 0.2) \times 10^{4}$ & $(10.0 \pm 0.4) \times 10^{4}$ & - & $(32.8 \pm 6.5) \times 10^{4}$ & $(26.7 \pm 5.7) \times 10^{6}$ \\
$n$ & $1.9 \pm 0.1$ & $3.6 \pm 0.4$ & $2.6 \pm 0.2$ & $4.1 \pm 0.6$ & $2.3 \pm 0.1$ \\
$\omega$ & $1.3 \pm 0.2$ & $0.30 \pm 0.05$ & - & - & - \\
\hline
\end{tabular}

$K_{1}$ is the external binding constant $(\mathrm{l} / \mathrm{mol}), K_{2}$ the intercalation binding constant $(\mathrm{l} / \mathrm{mol}), n$ the average number of binding sites occupied by a ligand, and $\omega$ the cooperativity parameter.

\subsubsection{Comparison of binding parameters}

Since amitozinoberamid is a medical antitumor drug, it is expedient to compare the parameters of the amitozinoberamid complex formation with the corresponding parameters for the berberine and sanguinarine alkaloids. The latter were studied by us earlier [9-11]. They exhibit antitumor properties and enter another antitumor preparation, amitozyn, developed at the IMBG NASU. The parameters of the thiotepa binding are also shown in Table.

As one can see, the intercalation (complete or partial) is a dominant type of binding for all three preparations - berberine, thiotepa, and amitozinoberamid - if they interact with DNA separately. However, if two preparation, berberine and thiotepa, are used to create the third one, amitozinoberamid, there arises some competition for the binding between two parts of the new molecule. In this case, the

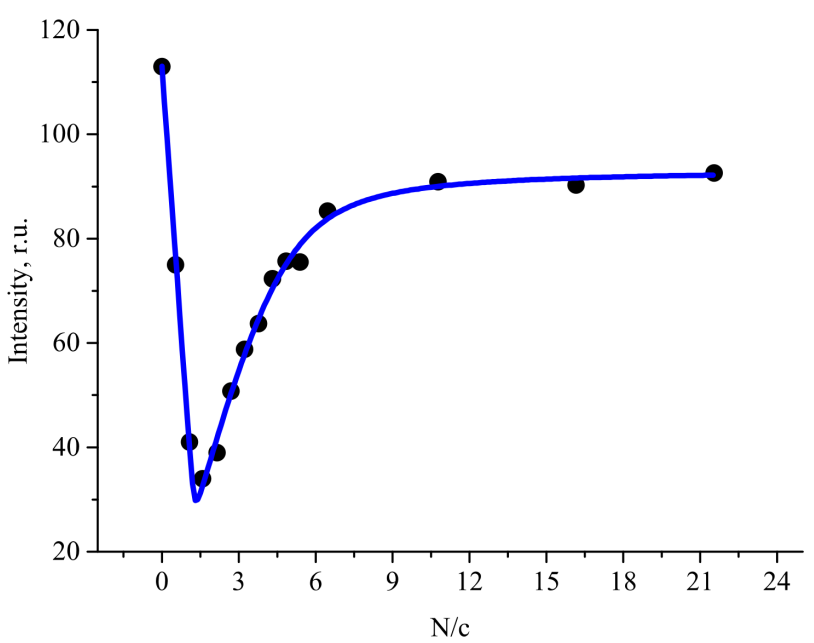

Fig. 12. Dependence of the sanguinarine fluorescence intensity (the $587-\mathrm{nm}$ band) on $N / c[9]$ berberine part binds with the DNA matrix, mainly by the intercalation mechanism, and blocks the same binding for the thiotepa part of the molecule. The latter, in turn, binds to DNA by the external binding of the head-to-tail type (the orientation of dipole moments), which is confirmed by the hyperchromism observed at $N / c>2$, i.e. in the whole interval of the external binding (Fig. 5). An indirect confirmation of the external binding of "thiotepa" is a relatively small value of $n(n \approx 4)$, which should be considerably larger for other types of external binding. However, the other types of the external binding have a low probability for the given molecular structure. Moreover, the separate binding of thiotepa to DNA is anticooperative. At the same time, the values of amitozinoberamid binding constants are higher than those for berberine and thiotepa, which is in agreement with the results of researches dealing with other types of modified berberine $[13,14]$.

When comparing with sanguinarine - namely, its imine form, which binds to DNA more efficiently than the alkanolamine one - it is of interest to compare the forms of binding curves rather than the values of binding constants. For Sa, this curve (Fig. 12) looks differently than those for Be (Fig. $9[9,11])$ and AmBe (Fig. 11). Probably, those three types of binding curves describe the binding of small ligands to DNA (the binding curve for ethidium bromide [11] has a slightly S-like shape, but it can be considered as a variant of the "Be-type" curve). Furthermore, for $\mathrm{Sa}$ and $\mathrm{AmBe}$, the sections of the curves corresponding to the external binding (i.e. in definite intervals of $N / c$-values) pronouncedly manifest themselves. At the same time, for Be, the external binding (which can be observed at very small $N / c$-values) can be almost neglected.

ISSN 2071-0194. Ukr. J. Phys. 2018. Vol. 63, No. 8 
From the aforesaid, one can see that sanguinurine binds more effectively to DNA than berberine, thiotepa, and amitozinoberamid: the binding constants for sanguinarine are larger. This circumstance can be explained by the fact that the sanguinarine molecule is planar [22] and, hence, is more prone to the intercalation than $\mathrm{Be}$ (a little bent [16], although it belongs to the same structural group as the Sa molecule), Thio (nonplanar), and AmBe (nonplanar and with a "tail") molecules. Since the medicobiological effect of Sa slightly differs from that of Be, Tio, and AmBe, we cannot assert about the relatively high antitumor effect of the sanguinarine preparation.

\section{Conclusions}

By analyzing the spectra of electron absorption and fluorescence of aqueous AmBe + DNA solutions, spectral modifications testifying to the binding of the amitozinoberamid preparation to DNA are detected, and the corresponding binding mechanism is established.

The dependence of the fluorescence intensity change at the maxima of the $\mathrm{AmBe}+\mathrm{DNA}$ fluorescence spectra on the ratio $N / c$ is determined. This dependence is non-monotonic, and its form is a nontrivial result, which was revealed for the first time.

The intercalation was found to be a characteristic binding mechanism for thiotepa and berberine, which are the components, from which amitozinoberamid is formed. At the same time, in the case of amitozinoberamid, an important contribution, in addition to the intercalation, is made by the external binding. We assume that this is a result of the "domination" of the berberine part of the molecule over the thiotepa one, if the concentration of binding sites is low. With the help of the software BindFit, the binding parameters (the binding constants and the average number of binding sites occupied by a small molecule on the DNA matrix) are determined.

Amitozinoberamid is found to bind to DNA more efficiently than berberine does. This conclusion confirms the results of previous medical and biological researches.

As an auxiliary result, the geometric structures of aziridine, thiotepa, and amitozinoberamid molecules are optimized, by using the DFT method, and their electron absorption spectra are calculated.
1. L.M. Guaman Ortiz, P. Lombardi, M. Tillhon, A.I. Scovassi. Berberine, an epiphany against cancer. Molecules 19, 12349 (2014).

2. Y. Cai, Q. Xia, R. Luo, P. Huang, Y. Sun, Y. Shi, W. Jiang. Berberine inhibits the growth of human colorectal adenocarcinoma in vitro and in vivo. J. Natur. Med. 68, 53 (2014).

3. Y.-S. Seo, M.-J. Yim, B.-H. Kim, K.-R. Kang, S.-Y. Lee, J.-S. Oh, J.-S. You, S.-G. Kim, S.-J. Yu, G.-J. Lee, D.K. Kim, C.S. Kim, J.-S. Kim. Berberine-induced anticancer activities in $\mathrm{FaDu}$ head and neck squamous cell carcinoma cells. Oncol. Rep. 34, 3025 (2015).

4. J.B. Patil, J. Kim, G.K. Jayaprakasha. Berberine induces apoptosis in breast cancer cells (MCF-7) through mitochondrial-dependent pathway. Eur. J. Pharm. 645, $70(2010)$.

5. S.M. Meeran, S. Katiyar, K. Katiyar. Berberine-induced apoptosis in human prostate cancer cells is initiated by reactive oxygen species generation. Toxicol. Appl. Pharm. 229, 33 (2008).

6. T.L. Serafim, P.J. Olivaira, V.A. Sardao, E. Perkins, D. Parke, J. Holy. Different concentrations of berberine result in distinct cellular localization patterns and cell cycle effects in a melanoma cell line. Cancer Chemoth. Pharm. 61, 1007 (2008).

7. A. Grebinyk, V. Yashchuk, N. Bashmakova, D. Gryn, T. Hagemann, A. Naumenko, N. Kutsevol, T. Dandekar, M. Frohme. A new triple system DNA-NanosilverBerberine for cancer therapy. Appl. Nanosci. 2018, 1 (2018).

8. N. Bashmakova, S. Kutovyy, V. Yashchuk, D. Hovorun, V. Losytskyy, L. Zaika. Optical spectroscopy studies of the interaction between a number of plant alkaloids and the DNA double helix in an aqueous solution. Ukr. J. Phys. 54, 471 (2009).

9. V.G. Gumenyuk, N.V. Bashmakova, S.Yu. Kutovyy, V.M. Yashchuk, L.A. Zaika. Binding parameters of alkaloids berberine and sanguinarine to DNA. Ukr. J. Phys. 56, 525 (2011).

10. S.Yu. Kutovyy, R.S. Savchuk, N.V. Bashmakova. Parameters of sanguinarine alkaloid binding with DNA. Visn. Kyiv. Univ. Ser. Fiz. Mat. Nauky No. 3, 265 (2014) (in Ukrainian).

11. V. Gumenyuk, S. Kutovyy, T. Sych, R. Savchuk, N. Bashmakova, Peculiarities of the binding of some small ligands to DNA. Mol. Cryst. Liq. Cryst., 589, 242 (2014).

12. S.Yu. Kutovyy, T.P. Sych, L.A. Zaika. Features of ethydium bromide and acridine orange binding to DNA. Visn. Kyiv. Univ. Ser. Fiz. Mat. Nauky No. 3, 273 (2014) (in Ukrainian).

13. D. Bhowmik, B. Franco, F. Gaetano, O. Fabrizio, T.M. Syeda, L. Paolo, G.S. Kumar. Synthesis of new 13diphenylalkyl analogues of berberine and elucidation of their base pair specificity and energetics of DNA binding. Med. Chem. Commun. 5, 226 (2014). 
14. D. Bhowmik, H. Maidul, B. Franco, D. Rosaria, L. Paolo, G.S. Kumar. Biophysical studies on the effect of the 13 position substitution of the anticancer alkaloid berberine on its DNA binding. J. Phys. Chem. 116, 2314 (2012)

15. A.I. Potopalskyy, S.T. Rybalko, A.O. Filchenkov, M.P. Zavelevych. Amitozinoberamid as an inhibitor of herpes virus replication. Patent of Ukraine for Utility Model No. 55573 (2010).

16. V.I. Danilov, V.V. Danilidonis, D.M. Hovorun, N. Kurita, Y. Murayama, T. Natsume, A.I. Potopalsky, L.A. Zaika. Berberine alkaloid: quantum chemical study of different forms by the DFT and MP2 methods. Chem. Phys. Lett. 430, 409 (2006).

17. N. Bashmakova, S. Kutovyy, R. Zhurakivsky, D. Hovorun, V.Yashchuk. Vibrational spectra of berberine and their interpretation by means of DFT quantum-mechanical calculations. Ukr. J. Phys. 56, 130 (2011).

18. K.-W. Kim, J.K. Roh, H.-J. Wee, C. Kim. Cancer Drug Discovery: Science and History (Springer, 2016).

19. G. Scatchard. The attractions of proteins for small molecules and ions. Ann. N. Y. Acad. Sci. 51, 660 (1949).

20. J.D. McGhee, P.H. von Hippel. Theoretical aspects of DNA-protein interactions: co-operative and non-cooperative binding of large ligands to a one-dimensional homogeneous lattice. J. Mol. Biol. 86, 469 (1974).

21. T. Nikolaienko, L. Bulavin, L.Sukhodub. The complexation of the anticancer drug ThioTEPA with methylated DNA base guanine: combined ab initio and QTAIM investigation. Mol. Informat. 33, 104 (2014).
22. A.P. Orekhov. Chemistry of Alkaloids (Akad. Nauk SSSR, 1955) (in Russian).

Received 02.05.18.

Translated from Ukrainian by O.I. Voitenko

С.Ю. Кутовий, Р.С. Савчук,

Н.В. Башмакова, Д.М. Говорун, Л.А. Заӥка

МЕХАНІЗМИ ТА ПАРАМЕТРИ

ЗВ'ЯЗУВАННЯ АМІТОЗИНОБЕРАМІДУ

З ДНК У ВОДНОМУ РОЗЧИНІ

$\mathrm{P}$ е $з$ ю м е

Методами оптичної спектроскопії - електронного поглинання та флюоресценції досліджено процеси взаємодії препарату амітозинобераміду (алкілований тіотефом берберин) 3 макромолекулою ДНК, у водному розчині. На основі отриманих результатів побудовано залежності спектральних характеристик від $N / c$ - відношення концентрації пар основ ДНК до концентрації молекул ліганду. Користуючись системою модифікованих рівнянь Скетчарда та МакГі-фон Хіппеля, визначено параметри зв'язування амітозинобераміду з ДНК. Проведено порівняльний аналіз ефективності взаємодії з ДНК амітозинобераміду та алкалоїдів берберину і сангвінарину. Методом функціонала густини на рівні теорї DFT B3LYP/6-31G(d,p) розраховано структуру та спектри електронного поглинання молекул тіотефу, берберину та амітозинобераміду. 